\title{
STUDY ON PERMEABILITY AND ELECTRICAL RESISTIVITY OF RED CLAY CONTAMINATED BY CU²+
}

\author{
Rulong Ban ${ }^{1,2}$ Xuejun Chen ${ }^{1,2}$ Yu Song ${ }^{1,2}$ Pengyan Bi ${ }^{1,2}$ Xin Yang ${ }^{1,2}$ and Xiaochen \\ Zhang ${ }^{1,2}$
}

1. College of Civil and Architectural Engineering, Guilin University of technology, Guilin541004, China1023095210@qq.com

2. Guangxi Key Laboratory of Mechanics and Geotechnical Engineering, Guilin541004, China

\begin{abstract}
In order to study the permeability characteristics of heavy metal ions contaminated red clay and explore the rapid detection of permeability of heavy metal contaminated red clay. Through variable-head permeability test and electrical resistivity test (different voltages and methods), the effects of $\mathrm{Cu}^{2+}$ concentration and initial water content on hydraulic conductivity characteristic and resistivity of contaminated red clay was systematically investigated. The relationship between permeability characteristic and electrical resistivity was further explored by taking $\mathrm{Cu}^{2+}$ concentration and moisture content as the intermediate variable. The obtained results indicate that the different voltage has no obvious effect on the resistivity of the samples. The four-phase electrode method is more accurate than the two-phase electrode method. With increasing $\mathrm{Cu}^{2+}$ concentrations the hydraulic conductivity of specimens increases, however the permeability coefficient of contaminated soil decreases with increasing initial water content. In the resistivity test, with increasing of $\mathrm{Cu}^{2+}$ concentrations and water content, the resistivity of samples presented a downward trend, which is decreased sharply at first and then tended to be gentle. The relationship between hydraulic conductivity and resistivity of contaminated soil showed a good fitting curve no matter in different $\mathrm{Cu}^{2+}$ concentration or in different water content, but the fitting curves of them presented opposite trend.
\end{abstract}

\section{KEYWORDS}

Red clay, Moisture content, $\mathrm{Cu}^{2+}$ pollution, Hydraulic conductivity, Resistivity

\section{INTRODUCTION}

Red clay is a kind of high plastic clay with special engineering mechanical characteristics formed by weathering of carbonate rock [1]. The rapid development of industry and agriculture has also brought about serious pollution problems. About $90 \%$ of the polluted soil is related to heavy metals. Copper ion is a common environmental pollution, which has the characteristics of high accumulation, easy migration and persistence[2-3].Therefore, it is necessary to study the permeability characteristics of heavy metal contaminated soil in order to effectively prevent and control the pollution of soil and groundwater in polluted areas, and to improve the strength of foundation soil and the actual construction quality.

At present, scholars have carried out some related research on the permeability of contaminated soil. According to the variable-head test, the permeability of clay decreases after being polluted by domestic waste, and the hydraulic conductivity increases gradually with the increase of contaminated depth [4]. By studying the influence of acid rain on the properties of red clay, it is found that the smaller $\mathrm{pH}$ value of acid rain, the greater influence on permeability and the 
permeability coefficient decreased with the increase of acid concentrations[5-6].The results show that the higher the concentration of heavy metal ions, the higher the hydraulic conductivity of contaminated soil[7-9].It is found that alkali and zinc pollution has great influence on the permeability of soil, and it is related to the infiltration time[10].The influence of heavy metal pollution on soil microstructure and permeability was studied through laboratory tests[11-12].It is found that the concentration of $\mathrm{Ca}^{2+}$ has a great influence on the permeability of bentonite sand mixture[13].For the above traditional experimental methods, although the exact test results can be obtained, it is expensive and time-consuming. As an important branch of geophysical methods, resistivity has been widely used in geotechnical engineering research because of its continuous, rapid and non-destructive characteristics [14]. The relationship between resistivity and permeability coefficient has been studied by scholars. Through the test of cement mixed soft clay and resistivity, the permeability of resistivity reaction is in good agreement with that of consolidation test[15].In order to understand the ability of rock to allow fluid to pass through, the resistivity and permeability characteristics are simulated to better understand the relationship between fractured rock and them[16].Taking structure factor and porosity as intermediate variables, calculate the relationship between permeability coefficient and resistivity of sand, and the feasibility of the formula is verified by experiments[17].At present, there are relatively few researches on the relationship between soil permeability and electrical resistivity, and the relationship between resistivity and other parameters is still in the initial stage, especially the research on the permeability and resistivity of heavy metal contaminated red clay is even less. Therefore, it is worth studying how to quickly detect its hydraulic conductivity.

Taking Guilin Red Clay as the research object, the influence of pollutant concentration and water content on the permeability and resistivity of contaminated soil was studied through the variable-head test and electrical resistivity test, respectively. The relationship between resistivity and hydraulic conductivity is further discussed through $\mathrm{Cu}^{2+}$ concentration and different water content as intermediate variables. It is expected that this investigation will give a certain reference value for the engineering applications of contaminated soil.

\section{METHODS}

\section{Materials}

The red clay used in the test was collected from a construction site in Yanshan Town, Guilin City, China at a depth of approximately $3 \mathrm{~m}$. It was a residual layer of Upper Pleistocene series $\left(\mathrm{Q}_{3}{ }^{\mathrm{e}}{ }^{1}\right)$, which was brownish red and was not polluted by $\mathrm{Cu}^{2+}$. After sampling, the red clay was first air-dry under the ambient condition, then ground and sieved to pass a $2 \mathrm{~mm}$ sieve [18]. Basic physical indexes of soil are summarized in Table 1. The liquid limit and plastic index of the natural res clay are $45.64 \%$ and $33.8 \%$, respectively. The maximum dry density and optimum moisture content of red clay obtained from the standard proctor compaction test were $1.536 \mathrm{~g}^{\circ} \mathrm{cm}^{-3}$ and $30 \%$, respectively. In this experiment, the $\mathrm{Cu}^{2+}$ contaminated solution is a $\mathrm{CuSO}_{4}$ solution prepared by $\mathrm{CuSO}_{4} \cdot 5 \mathrm{H}_{2} \mathrm{O}$ crystal (analytical pure) and deionized water. 


\begin{tabular}{cc} 
Tab. 1 - Basic physical properties of red clay \\
\hline Parameter & Value \\
\hline $\begin{array}{c}\text { Liquid limit } \\
\text { WL }(\%)\end{array}$ & 45.64 \\
\hline $\begin{array}{c}\text { Plastic limit } \\
\text { WP }_{\text {( } \%)}\end{array}$ & 33.18 \\
\hline $\begin{array}{c}\text { Plasticity index } \\
\text { IP }\end{array}$ & 12.46 \\
\hline $\begin{array}{c}\text { Optimum moisture } \\
\text { content }(\%)\end{array}$ & 30.00 \\
\hline $\begin{array}{c}\text { Maximum dry } \\
\text { density }\left(g^{\circ} \mathrm{cm}^{-3}\right)\end{array}$ & 1.536 \\
\hline $\begin{array}{c}\text { Specific gravity } \\
\mathrm{G}_{\mathrm{s}}\end{array}$ & 2.70 \\
\hline
\end{tabular}

\section{Specimen preparation}

The $\mathrm{Cu}^{2+}$ concentrations and initial water content were selected $0 \mathrm{~g} / \mathrm{L}, 0.5 \mathrm{~g} / \mathrm{L}, 1 \mathrm{~g} / \mathrm{L}, 5 \mathrm{~g} / \mathrm{L}$, $10 \mathrm{~g} / \mathrm{L}$ (according to the regional pollution assessment report) and $20 \%, 25 \%, 30 \%, 35 \%$, respectively. When studying the effect of $\mathrm{Cu}^{2+}$ concentrations, the initial water content was fixed at optimum moisture content $30 \%$. When studying the influence of initial water content, the $\mathrm{Cu}^{2+}$ concentrations was fixed at $0.5 \mathrm{~g} / \mathrm{L}$.

The air-dry and sieves soil was first mixed with a predetermined amount of heavy metal solution to reach the desired water content. After mixing, the wet contaminated red clay mixtures were stored in a sealed plastic bag and placed in the standard curing chamber (temperature of $23^{\circ} \mathrm{C}$, humidity $\geq 90 \%$ ) for at least $24 \mathrm{~h}$ for homogenization. Then, the homogenous contaminated soil were placed into a cylindrical steel mold, and compacted by using a hydraulic jack to achieve the same dry density $1.45 \mathrm{~g}^{\circ} \mathrm{cm}^{-3}$, which was controlled at $95 \%$ of the maximum dry density, because the sample could be consistently made and smoothy demolded. According to the Standard for Soil Test Method [19], the samples used for hydraulic conductivity test shall have a specified size $(61.8 \mathrm{~mm} \times 40 \mathrm{~mm})$ and prepared 5 parallel samples for each initial parameters. Specimens of permeability test were placed into vacuum saturation device, vacuum for $2 \mathrm{~h}$ and then deionized water was pumped into the device to cover samples for $12 \mathrm{~h}$ in order to samples saturated. According to previous studies[14,25] the specimens used for electrical resistivity test shall use improved Miller Soil Box $(5 \mathrm{~cm} \times 15 \mathrm{~cm})$ to test and prepared 3 parallel samples for each initial parameters, thereafter, the samples of electrical resistivity test were sealed in the plastic bags.

\section{Test methods}

\section{Hydraulic conductivity test}

Permeability test was performed according to JTG2007[18], the laboratory test on hydraulic conductivity usually includes the constant-head and variable-head permeability test, which are applied for highly hydraulic conductivity coarse soil and low-permeability fine soil, respectively. The permeability test of red clay was suitable for the variable-head method as shown in Figure1. Samples are recorded water level height difference and falling time, respectively, and measured water temperature at the same time. The permeability coefficient can be calculated by the following equation:

$$
k=\left[2.3 \frac{a \cdot L}{A\left(t_{2}-t_{1}\right)} \log \frac{H_{1}}{H_{2}}\right] \cdot \eta
$$


Where $k$ is the permeability coefficient $(\mathrm{cm} / \mathrm{s})$; $a$ is the cross-sectional area $\left(\mathrm{cm}^{2}\right)$ of glass tube; $L$ is the heigh $(\mathrm{cm})$ of specimen; $\mathrm{t}_{1}$ and $\mathrm{t}_{2}$ are the beginning time and ending time, respectively; $\mathrm{H}_{1}$ and $\mathrm{H}_{2}$ are beginning water head and ending water head, respectively; $\eta$ is coefficient of viscosity under different temperature. According to the Standard for Soil Test Method [19], the data collected is based on the average of the 24 times measurement of permeability coefficient.

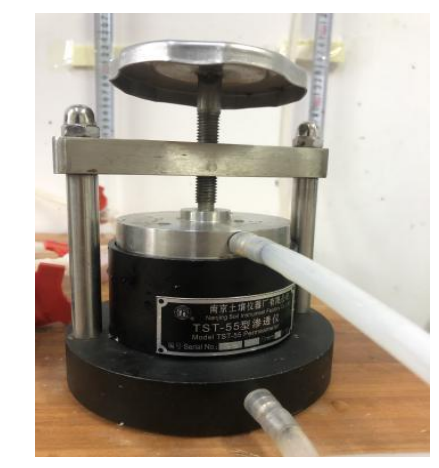

Fig.1 - TST-55 Osmometer

\section{Electrical resistivity test}

At present, the resistivity tests on soil usually include two-phase electrode and four-phase electrode method, two-phase and four-phase method interaction was adopted in this study by using the VC4091C LCR precision digital bridge $(0.0001 \Omega \sim 99.999 \mathrm{M} \Omega)$ and set parameters as low-frequency and AC. The current frequency in this paper is based on the $50 \mathrm{~Hz}$ adopted by most scholars in China [20-21]. The resistivity of soil was calculated by following equation:

$$
\rho=\frac{V \cdot A}{I \cdot L}
$$

where $V$ is the measured voltage; $A$ is area(cm2) of specimen; I is the measured current; $L$ is the length between copper bars. The overall schematic diagram is shown in Figure 2(a) and the overall test diagram is shown in Figure 2(b).

(a)

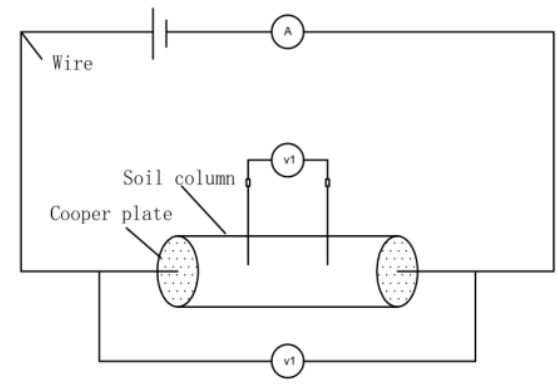

(b)

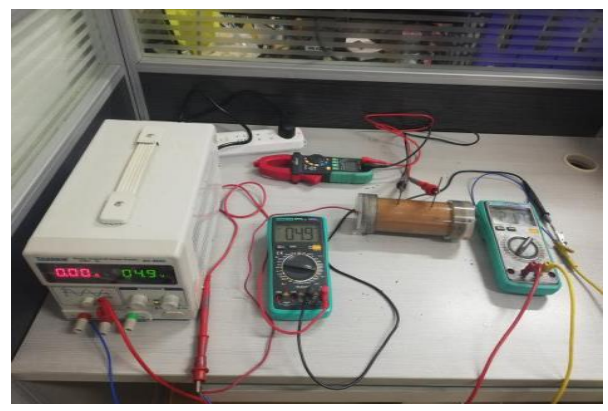

Fig.2 (a)- Schematic diagram for resistivity test; (b) The chart of overall test

\section{ANALYSIS OF THE RESULTS AND DISCUSSION \\ Influence of $\mathrm{Cu}^{2+}$ concentration on permeability of red clay}

According to the recorded data, the excessive variation of permeability coefficient is removed, and then the corresponding permeability coefficient is obtained by averaging it, and the change diagram of $\mathrm{Cu}^{2+}$ concentration and permeability coefficient is drawn. As shown in Figure 3 it can be seen that the permeability coefficient of red clay ranges from $3.54 \times 10^{-6} \mathrm{~cm} / \mathrm{s}$ to $42.25 \times 10^{-}$ 
${ }^{6} \mathrm{~cm} / \mathrm{s}$, and increases with the increase of $\mathrm{Cu}^{2+}$ concentration. When the concentration is greater than $0.5 \mathrm{~g} / \mathrm{L}$, the permeability coefficient changes more obviously with the increase of $\mathrm{Cu}^{2+}$ concentration. When the copper ion concentration is greater than $5 \mathrm{~g} / \mathrm{L}$, the permeability coefficient increases slowly. Analyze the reasons: red clay is a special soil, and its engineering characteristics are inseparable from the cementation between soil particles [22]. Due to the complex physical and chemical reaction between $\mathrm{Cu}^{2+}$ and red clay soil particles, the chemical composition has changed[23].When the $\mathrm{Cu}^{2+}$ concentration is small, a small amount of $\mathrm{Cu}^{2+}$ will be hydrolyzed, and a small amount of $\mathrm{Cu}(\mathrm{OH})_{2}$ colloid will be produced. However, the acidity of the solution is too weak to react with the cementation material between the soil particles to form a small amount of $\mathrm{Fe}^{2+}, \mathrm{Fe}^{3+}, \mathrm{Al}^{3+}$, etc. , which results in less erosion of clay mineral flakes and micro crystalline free iron oxide "coating", and the cementation between particle cluster is not significantly weaken. Although the number of small soil particles increased during this process, the large clusters of particles did not decrease significantly. Therefore, when the concentration of $\mathrm{Cu}^{2+}$ is $0.5 \mathrm{~g} / \mathrm{L}$, the permeability coefficient of red clay is not significantly increased compared with that of uncontaminated soil. With the increase of $\mathrm{Cu}^{2+}$ content, the acidity of the solution becomes stronger, which will obviously dissolve the crystalline free iron oxide and other cementing substances between the particles, the cementation between the soil particles will weaken, and the diffusion double layer will also become thinner, the repulsive force among soil particles is weakened, and small particles will agglomerate to cause the pore size to change from tiny pores to small pores, mesopores or even large pores, and then the effective pore transportation channel of the soil will be enlarged. Therefore, when the concentration of $\mathrm{Cu}^{2+}$ is greater than $1 \mathrm{~g} / \mathrm{L}$, the permeability coefficient of red clay increases obviously, and the higher the concentration of polluted liquid, the higher the permeability coefficient.

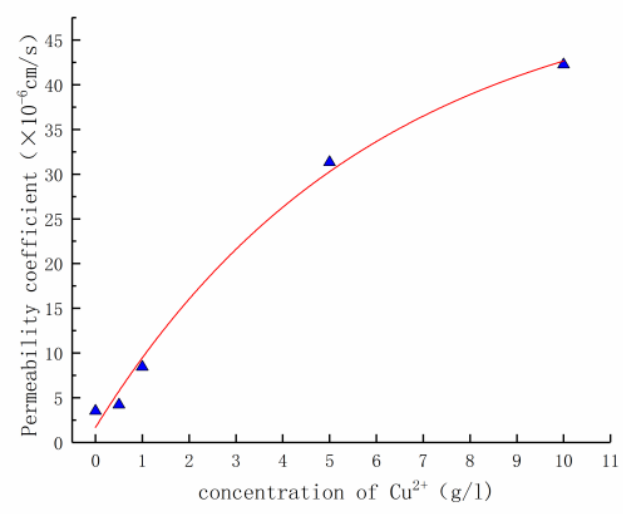

Fig.3 - Relation curve between permeability coefficient of red clay and $\mathrm{Cu}^{2+}$ concentration

\section{Influence of moisture content on permeability of red clay}

The concentration of contaminated solution is $0.5 \mathrm{~g} / \mathrm{L}$, and the water content is $20 \%, 25 \%$, $30 \%$ and $35 \%$ respectively, the variation law of permeability coefficient of soil sample is shown in Figure 4 It can be seen from Figure 4 that the permeability coefficient of the soil sample decreases with the increase of moisture content. The main reasons are as follows: The binding materials in red clay are mainly $\mathrm{Fe}_{2} \mathrm{O}_{3}, \mathrm{Al}_{2} \mathrm{O}_{3}$, etc. under dry conditions, the free ferric oxide between soil particles is mostly in the form of crystalline ferric oxide [24]. When the water content is low, the water molecules in the red clay are adsorbed by the clay minerals to form a strong bound water film, at this time, the bound water film is relatively weak, and the repulsion force between soil particles decreases, resulting in the combination of small particles to form a relatively stable particle structure, which makes the pores in the soil tend to widen and the effective transport pore channels enlarge. Hence, when the water content is low, the permeability coefficient of the sample 
is larger; When the water content increases to $30 \%$, due to the electric double layer structure of red clay has strong water absorption, with the increase of water molecules, the thin strong bound water film changes into the thick weak bound water film, and the crystal ferric oxide gradually changes into amorphous ferric oxide, so the attraction between soil particles is weakened, and the structure of particle group cannot be formed, and the soil sample pores are reduced, so in this stage, the permeability coefficient decreases rapidly; When the water content is as high as $35 \%$, due to the further increase of water molecules, the large pores between the soil particles have been gradually filled with water molecules, and the gravitational force between particles is further reduced, moreover, because the low concentration of $\mathrm{Cu}^{2+}$ makes the soil produce a bit of small particles, the pores can be effectively filled in the process of soil sample preparation. Therefore, when the optimal water content is exceeded, the permeability coefficient of soil will further decrease. And the permeability of red clay is mainly affected by water content when $\mathrm{Cu}^{2+}$ concentration is low.

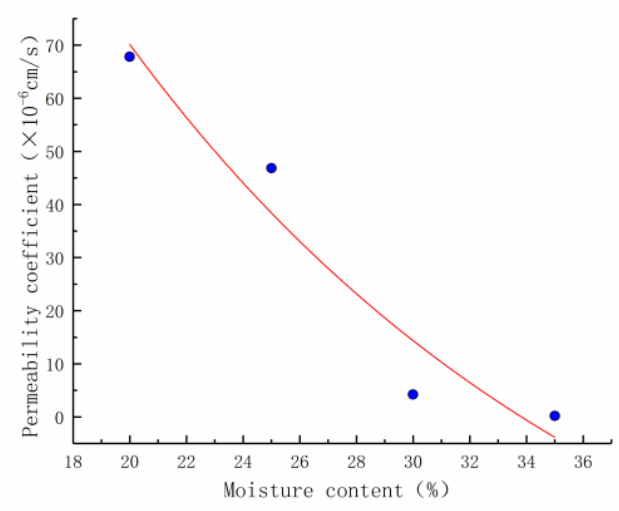

Fig.4 - Relationship curve between moisture content and permeability

\section{Relationship between $\mathrm{Cu}^{2+}$ concentration and resistivity}

According to the resistance change value measured under different voltage and formula $\rho=R \frac{S}{L}$, the change diagram of $\mathrm{Cu}^{2+}$ concentration resistivity is obtained. In the formula: $\mathrm{R}$ is the measured resistance of the soil sample; $S$ is the cross-sectional area of the soil sample; $L$ is the distance between the two electrodes. As shown in Figure 5, $\rho 2$ and $\rho 4$ represent two-phase resistivity and four-phase resistivity respectively. It can be seen that the change of voltage has no obvious effect on the resistivity, no matter the two-phase electrode method or the four-phase electrode method, the relationship between the resistivity and $\mathrm{Cu}^{2+}$ concentration of contaminated red clay presents an exponential function relationship. With the increase of $\mathrm{Cu}^{2+}$ concentration, the resistivity $\rho 2$ and $\rho 4$ decrease rapidly, then gradually slow down, and finally tend to be stable. The reasons for the above rules are as follows: Because the soil is prepared with the optimal water content, the pore water connectivity between the red clay particles has reached a good state, so the conduction path is mainly between the pore liquid when the soil is electrified[25].After the red clay is contaminated, $\mathrm{Cu}^{2+}$ is more active in the pore fluid, under the action of the clay mineral flakes (kaolinite) with strong electrostatic attraction, it will be preferentially adsorbed to the fixed layer, and the conductivity of the fixed layer is much greater than The conductivity of the diffusion layer, so when the $\mathrm{Cu}^{2+}$ concentration is less than $5 \mathrm{~g} / \mathrm{L}$, the resistivity of the soil can be rapidly reduced; With the increase of $\mathrm{Cu}^{2+}$ concentration more than $5 \mathrm{~g} / \mathrm{L}$, the adsorption sites on the surface of clay minerals gradually reach saturation state. Then the surplus $\mathrm{Cu}^{2+}$ flows into the diffusion layer, which will produce complex physical and chemical reactions with various Cementitious substance between soil particles, and produce free $\mathrm{Fe}^{2+}, \mathrm{Fe}^{3+}, \mathrm{Al}^{3+}$, etc. plasma, the 
increase of the number of ions in the pore liquid leads to the increase of the current between the soil and the further decrease of the resistivity. However, the conductivity of the diffusion layer is far less than that of the fixed layer, so the decline of the resistivity becomes slower; When the concentration of $\mathrm{Cu}^{2+}$ reaches $10 \mathrm{~g} / \mathrm{L}$, the dissolution and loss of crystalline free iron oxide and other cementation materials among the particles are enhanced, the cementation between soil particles is weakened, and the pores between particles increase, resulting in the increase of inter particle spacing, the decrease of contact area and the decrease of current flow rate. Therefore, when the concentration of $\mathrm{Cu}^{2+}$ is further increased, the resistivity gradually tends to be flat.
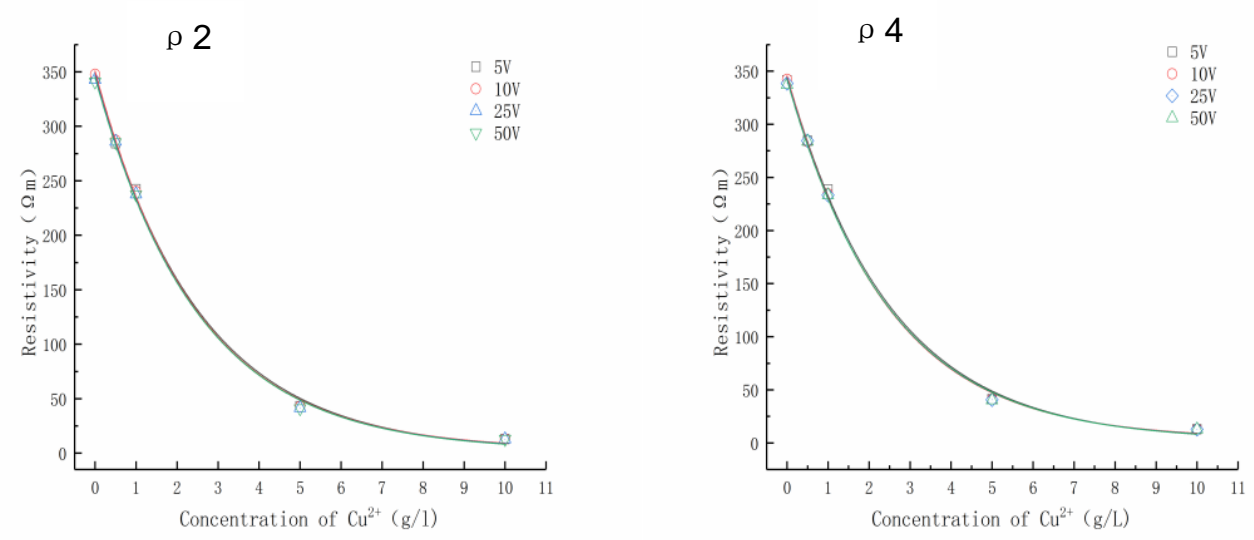

Fig.5 - Relation curves between $\mathrm{Cu}^{2+}$ concentration and resistivity

\section{Relationship between moisture content and resistivity}

Test the relationship between moisture content and resistivity under the condition of changing the voltage, and the data obtained is plotted as shown in Figure 6. It can be seen from the figure that the relationship between moisture content and resistivity and the relationship between $\mathrm{Cu}^{2+}$ concentration and resistivity show similar trends, showing a negative exponential correlation. Under different voltage, the resistivity corresponding to different water content has little difference. Under the voltage of $5 \mathrm{~V}$ for analysis, the range of resistivity measured by two-phase electrode method and four-phase electrode method is $548.41 \sim 267.12 \Omega \mathrm{m}$ and $462.5 \sim 262.48 \Omega \mathrm{m}$, respectively. It can be seen that the data measured by the four-phase electrode method is smaller than that by the two-phase electrode method when the water content is low. When the water content increases, the measurement results of the two methods are similar. The main reason is: when the water content is low, the conductive path is through the contact between soil particles, and a small amount of water and clay minerals to form a strong binding water film, because the water film is thin, the soil particles attract each other, and the water film contacts with each other, at the same time, the pore fluid increases correspondingly, which enhances the connectivity and further improves the soil conductivity. Therefore, the increase of a small amount of water will significantly increase the conductivity of the sample; When the water content continues to increase to $30 \%$, the strong bound water film begins to change into the weak bound water film and free water, and the pore between particles is filled by water, at this time, the conductive path begins to change to pore water and water-soil contact, the connectivity continues to increase, and the resistivity decreases; Continue to increase the water to a moisture content of $35 \%$, the pores between the soil particles in the sample are basically filled with water. the main conduction path is pore water, at this time, the improvement of conductivity is weak, so the increasing trend of resistivity slows down. The results of the two-phase electrode method test are affected by the contact resistance, and the lower the moisture content, the greater the contact resistance; after the moisture content increases, the sample is in good contact with the electrode sheet, and the contact resistance is very weak, so the test results of the two methods are similar[26]. 

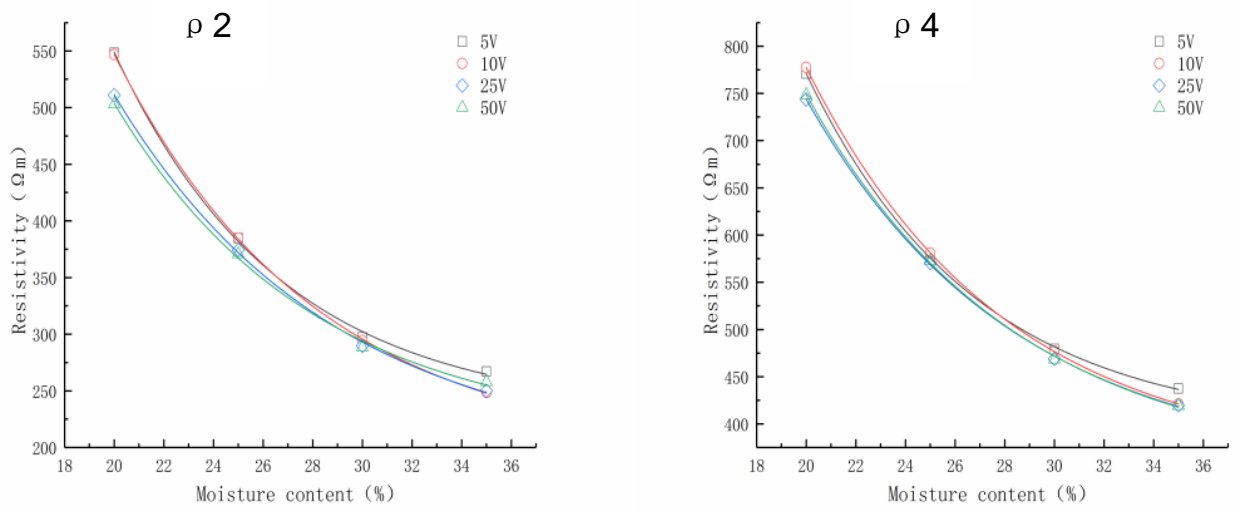

Fig.6 - Relation curves between moisture content and resistivity

\section{Relationship between resistivity and permeability coefficient}

Permeability coefficient reflects the difficulty of water flowing in soil pores, which is one of the important basic parameters of soil. Resistivity is one of the inherent physical properties of soil. Both of them are inherent parameters of soil, so the internal relationship between the two parameters is discussed. Now, taking $\mathrm{Cu}^{2+}$ concentration and water content as intermediate variables, the measured permeability coefficient of contaminated soil is correlated with the relative resistivity of contaminated soil, and find the relationship between the permeability coefficient and electrical property index of contaminated red clay under different $\mathrm{Cu}^{2+}$ concentration and water content. Figure 7 shows the relationship between permeability and resistivity of red clay polluted by different $\mathrm{Cu}^{2+}$ concentration; Figure 8 shows the relationship between permeability coefficient and resistivity of red clay under different moisture content.

$\rho 2$

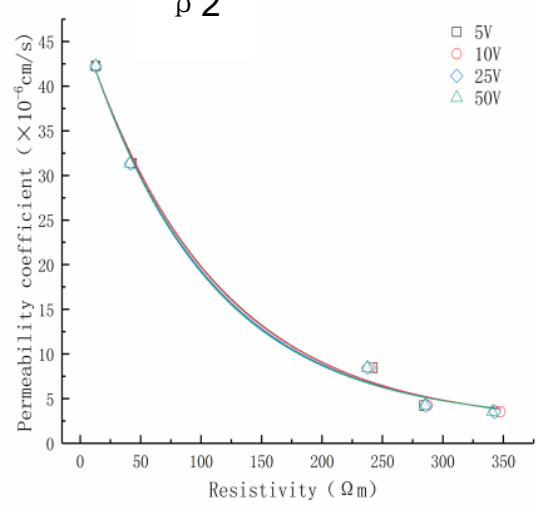

$\rho 4$

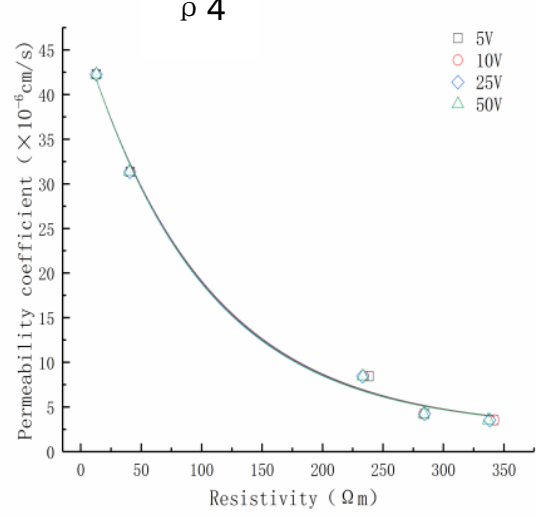

Fig.7 - Relation curves between permeability and resistivity under different $\mathrm{Cu}^{2+}$ concentrations 
$\rho 2$

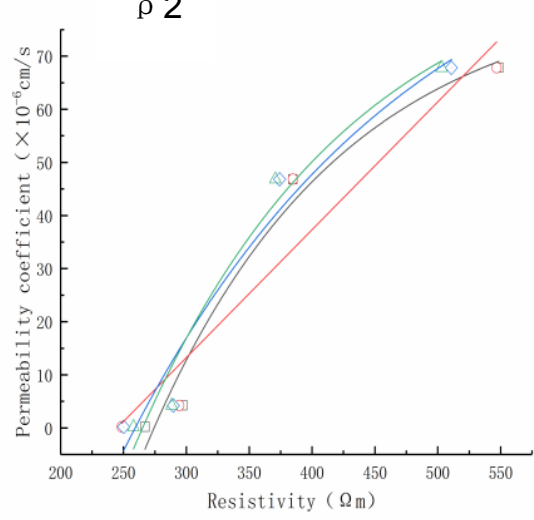

$\rho 4$

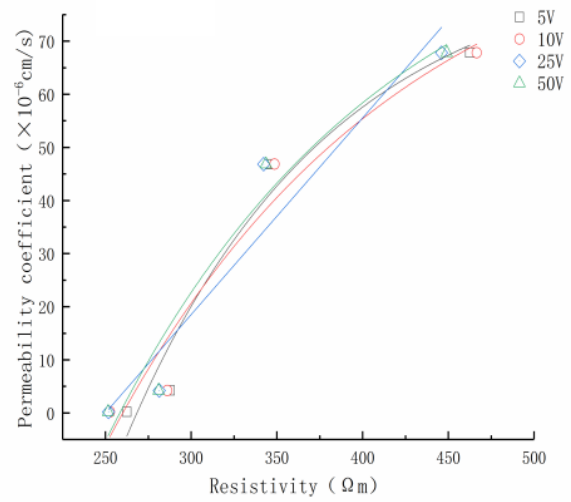

Fig. 8 - Relation curves between permeability and resistivity under different moisture content

It can be seen from Figure 7 that the permeability coefficient under different voltage and different $\mathrm{Cu}^{2+}$ concentration has a good exponential function relationship with the resistivity measured by the two-phase electrode method and the four-phase electrode method. The permeability coefficient decreases with the increase of the resistivity. The fitting formula is shown in Table 2. Figure 8 shows the relationship between the permeability coefficient under different voltages and different water content conditions and the resistivity changes measured by the two electrode methods, both showing a better fitting curve, and the greater the resistivity, the permeability coefficient increases. The fitting formula is shown in Table 3.

Tab. 2 - Relations between permeability and resistivity under different $\mathrm{Cu}^{2+}$ concentrations

\begin{tabular}{|c|c|c|c|}
\hline $\begin{array}{c}\text { Electrode } \\
\text { method }\end{array}$ & $\begin{array}{c}\text { Voltage } \\
\text { (V) }\end{array}$ & Fitting formula & $\mathrm{R}^{2}$ \\
\hline \multirow{4}{*}{$\rho 2$} & 5 & $k=44.76 \times \exp (-\rho 2 / 108.66)+1.99$ & 0.99623 \\
\hline & 10 & $k=44.72 \times \exp (-\rho 2 / 107.26)+2.12$ & 0.99649 \\
\hline & 25 & $k=44.61 \times \exp (-\rho 2 / 103.97)+2.30$ & 0.99628 \\
\hline & 50 & $k=44.57 \times \exp (-\rho 2 / 102.09)+2.42$ & 0.99606 \\
\hline \multirow{4}{*}{$\rho 4$} & 5 & $k=44.55 \times \exp (-p 4 / 102.01)+2.44$ & 0.9959 \\
\hline & 10 & $k=44.63 \times \exp (-\rho 4 / 101.31)+2.42$ & 0.99629 \\
\hline & 25 & $k=44.61 \times \exp (-p 4 / 100.75)+2.43$ & 0.99629 \\
\hline & 50 & $k=44.58 \times \exp (-\rho 4 / 99.73)+2.50$ & 0.99611 \\
\hline \multicolumn{4}{|c|}{ Tab.3 - Relations between permeability and resistivity under different moisture content } \\
\hline $\begin{array}{c}\text { Electrode } \\
\text { method }\end{array}$ & $\begin{array}{l}\text { Voltage } \\
\text { (V) }\end{array}$ & Fitting formula & $\mathrm{R}^{2}$ \\
\hline \multirow{5}{*}{$\rho 2$} & 5 & $\mathrm{k}=-495.0 \times \exp (-\rho 2 / 153.56)+82.93$ & 0.97221 \\
\hline & 10 & $k=1.12 \times \exp (-\rho 2 /-4.67)-1.12$ & 0.92174 \\
\hline & 25 & $k=-332.79 \times \exp (-\rho 2 / 229.03)+104.04$ & 0.95988 \\
\hline & 50 & $\mathrm{k}=-431.16 \times \exp (-\rho 2 / 172.01)+92.25$ & 0.97122 \\
\hline & 5 & $\mathrm{k}=-818.59 \times \exp (-\rho 4 / 119.17)+86.11$ & 0.96034 \\
\hline \multirow{3}{*}{$\rho 4$} & 10 & $k=-456.44 \times \exp (-\rho 4 / 169.9)+98.73$ & 0.94924 \\
\hline & 25 & $\mathrm{k}=1.12 \times \exp (-\rho 4 /-3.04)+-1.12$ & 0.92724 \\
\hline & 50 & $k=-491.9 \times \exp (-\rho 4 / 162.64)+100.44$ & 0.95878 \\
\hline
\end{tabular}


In the formula: $k$ is the permeability coefficient; $\rho 2$ is the resistivity obtained by the twophase electrode method; $\rho 4$ is the resistivity obtained by the four-phase electrode method. The correlation coefficients $R^{2}$ are all above 0.9 , and the correlation degree is high. It can be proved that the combination of permeability coefficient and resistivity is feasible to evaluate the permeability of heavy metal contaminated red clay. The resistivity method combined with the above formula can quickly detect the permeability coefficient under different water content and different concentration of pollution ions, which provides a convenient method for the construction and treatment of actual contaminated sites.

\section{CONCLUSION}

1. When measuring resistivity with different electrode methods, the two-phase electrode method will be disturbed by the contact resistance compared with the four-phase electrode method. Therefore, in order to avoid modifying the resistivity value, the four-phase electrode method should be selected for measurement. Under the action of different voltages, the measured resistivity does not change obviously, so the voltage does not affect the value of resistivity.

2. With the increase of $\mathrm{Cu}^{2+}$ concentration, the permeability coefficient of red clay also increases, and the curve fitting is better; Under the condition of different water content, the permeability coefficient of soil presents the opposite trend to that under the action of ion concentration, and the permeability coefficient decreases with the increase of water content. When it is less than the optimal water content, the downward trend is obvious, and when it is greater than the optimal water content, the decline tends to be flat.

3. The resistivity curves corresponding to different $\mathrm{Cu}^{2+}$ concentration and water content show negative exponential correlation, which first decreases sharply with the increase of variables, gradually slows down, and finally tends to be stable.

4. The permeability coefficient of red clay has good fitting in the curves of $\mathrm{Cu}^{2+}$ concentration and resistivity, the curves of water content and resistivity, but their change trend is opposite. Under different $\mathrm{Cu}^{2+}$ concentrations, the permeability coefficient decreases with the increase of resistivity; In the case of different water content, the permeability coefficient increases with the increase of resistivity.

\section{ACKNOWLEDGEMENTS}

This work was supported by the Guilin Science and Technology Development Project (Grant no. 20170222).and the National Natural Science Foundation of China (Grant no. 41967037).

\section{REFERENCES}

[1] Chen X J, Xie T, Song Y, Yu Y.2015. Experimental study on soil tectonics characteristics of red clay in Guilin [J] Subgrade Engineering ,(04):72-75.

[2] Zhao J Y, Li Y, Li S S. 2013.Zhang S. Polluted soil remediation technology and industry status in China [J] China Environmental Protection Industry, (03):53-57.

[3] Dou X K. 2017.Contamination and Harm of Copper [J] Science, Technology and Economics Guide ,(08):126

[4] Wang Y, Cao L W, Wen W F, Huo P. 2014.Microstructure and Permeability of domestic waste contaminated clays [J] Hydrogeological \& Engineering Geology ,41(02):138-142.

[5] Xiao G Y, Chen X J, Wei C F, Huang X, Chen L. 2016. Mechanism of permeability and control of compaction for red clay under the influence of acid rain [J] Chinese Journal of Rock Mechanics and Engineering ,35(S1):3283-3290. 
[6] Liu H, He J T, Zhao X, Wang T X, Guo C Y.2020.Experimental study on the evolution rules of micropermeability characteristics acid-contaminated undisturbed loess [J] Rock and Soil Mechanics ,41(03):765772.

[7] Zhang Z H, Li H Y, Chen J Y, Lei Y.2016.Permeability of saturated clay eroded by mixed heavy metal ions [J] Rock and Soil Mechanics ,37(09):2467-2476.

[8] Li K, Zhang D W, Cao Z G.2019. Effect of carbonation on permeability characteristics of cementstabilized/solidfied lead-contaminated soil [J] Chinese Journal of Geotechnical Engineering ,41(S2):117-120.

[9] Taheri, S. and T. Ebadi, et al. 2018. Predicting variations in the permeability and strength parameters of a sand-bentonite mixture (SBM) contaminated simultaneously with lead (II) and diesel. Applied Clay Science 157: 102-110.

[10] Wang W J, Chen Y, Jiang J L, Cai G C.2020.Experimental Study on compression and infiltration characteristics of silt clay contaminated by alkaline and zinc [J] Geotechnical investigation\&surveying,48(02):6-12.

[11] Nayak S,Sunil B M, Shrihari S.2007. Hydralic and compaction characteristics of leach atecontaminated lateritic soil [J]. Engineering Geology, 94(3-4): 134-144.

[12] Serranti S,Bonifazi G.2012.Pollution level detection in dump clay liners by hyperspeetral imaging [J]. International Journal of Environment and Waste Management, 10(2-3): 163-176.

[13] Xu, S. and M. Bian, et al. 2018.Effects of calcium concentration and differential settlement on permeability characteristics of bentonite-sand mixtures. Applied Clay Science 153: 16-22.

[14] Chu Y, Liu S Y, Cai G J, Bian H L.2015.An experimental study of physical and electrical characteristics of zinc contaminated silty soil [J] Rock and Soil Mechanics ,36(10):2862-2868.

[15] Khin.M.M.Latt, P.H. Giao. 2017. Prediction of permeability of cement-admixed soft clay using resistivity and time-domain IP measurements. Journal of Applied Geophysics 137: 92-103.

[16] Alison Kirkby, Graham Heinson. 2016. Three-dimensional resistor network modeling of the resistivityand permeability of fractured rocks. Journal of Geophysical Research:Solid Earth 122(4):2653-2669

[17] Peng C, Wang B H, Yuan Z H et al.2018. Investigation on permeability of sands based on electrical resistivity. Journal of Jiangsu University of Science and Technology 32(06): 891-897

[18] JTG E40 (2007) Test methods of soils for highway engineering. Industrial Standard of People's Republic of China, Ministry of communications, PRC

[19] Nanjing Hydraulic Research Institute.2019 Standard for soil test method(GB/T 5023-2019) [S]. Beijing: China Planning Press

[20] Liu G H, Wang Z Y, Huang J P.2004. Research on electrical resistivity feature of soil and it's application [J] Chinese Journal of Geotechnical Engineering ,(01):83-87.

[21] Liu S Y, Cha F S, Yu X J.2006.Laboratory measurement techniques of the electrical resistivity of soils [J] Journal of Engineering Geology ,(02):216-222.

[22] Song $Y$ and Yang $Y$ et al.2015.Characteristics and deformation mechanism of microstructure for red clay.[J] Journal of Geological Hazards and Environmental Protection ,26(03):73-76.

[23] Chen X J, Chen Y C, Song Y, Li J M, Yu S Z, Chen L J.2019.Analysis on variation of physicalmechanical properties of red clay contaminated by $\mathrm{Cu}^{2+}[\mathrm{J}]$ Journal of Engineering Geology ,27(05):10101018.

[24] Chen H B, Chen X J,Qi Y L et al.2019. Effects of dry density and moisture content on shear strength parameters of remolded red clay soil [J] . Journal of Engineering Geology, 27(5): 1035-1040

[25] Chen Y C, Huang X, Chen X J, Zhang X C, Ban R L.2020.Study on relationship between shear strength and electrical resistivity of $\mathrm{Cu}(2)$ contaminated red clay [J/OL] Journal of Yangtze River Scientific Institute, 1-13.

[26] Chen Y C, Song Y, Chen X J et al. 2020. Resistivity characteristics of red clay contaminated by $\mathrm{Cu}^{2+}$ [J] Rock and Soil Mechanics, 2020(S2): 1-10 